\title{
Antitumor HPV E7-specific CTL activity elicited by in vivo engineered exosomes produced through DNA inoculation
}

This article was published in the following Dove Press journal:

International Journal of Nanomedicine

23 June 2017

Number of times this article has been viewed

\author{
Paola Di Bonito' \\ Chiara Chiozzini ${ }^{2}$ \\ Claudia Arenaccio ${ }^{2}$ \\ Simona Anticoli ${ }^{2}$ \\ Francesco Manfredi ${ }^{2}$ \\ Eleonora Olivetta ${ }^{2}$ \\ Flavia Ferrantelli ${ }^{2}$ \\ Emiliana Falcone ${ }^{3}$ \\ Anna Ruggieri ${ }^{3}$ \\ Maurizio Federico ${ }^{2}$ \\ 'Department of Infectious, Parasitic \\ and Immunomediated Diseases, \\ Istituto Superiore di Sanità, Rome, \\ Italy; ${ }^{2}$ National AIDS Center, Istituto \\ Superiore di Sanità, Rome, Italy; \\ ${ }^{3}$ Department of Veterinary Public \\ Health and Food Safety, Istituto \\ Superiore di Sanità, Rome, Italy
}

\begin{abstract}
We recently proved that exosomes engineered in vitro to deliver high amounts of HPV E7 upon fusion with the Nef ${ }^{\text {mut }}$ exosome-anchoring protein elicit an efficient anti-E7 cytotoxic T lymphocyte immune response. However, in view of a potential clinic application of this finding, our exosome-based immunization strategy was faced with possible technical difficulties including industrial manufacturing, cost of production, and storage. To overcome these hurdles, we designed an as yet unproven exosome-based immunization strategy relying on delivery by intramuscular inoculation of a DNA vector expressing Nef ${ }^{\text {mut }}$ fused with HPV E7. In this way, we predicted that the expression of the $\mathrm{Nef}^{\text {mut }} / \mathrm{E} 7$ vector in muscle cells would result in a continuous source of endogenous (ie, produced by the inoculated host) engineered exosomes able to induce an E7-specific immune response. To assess this hypothesis, we first demonstrated that the injection of a Nef ${ }^{\text {mut }}$ /green fluorescent protein-expressing vector led to the release of fluorescent exosomes, as detected in plasma of inoculated mice. Then, we observed that mice inoculated intramuscularly with a vector expressing $\mathrm{Nef}{ }^{\text {mut}} / \mathrm{E} 7$ developed a $\mathrm{CD} 8^{+} \mathrm{T}$-cell immune response against both Nef and E7. Conversely, no $\mathrm{CD} 8^{+} \mathrm{T}$-cell responses were detected upon injection of vectors expressing either the wild-type Nef isoform of E7 alone, most likely a consequence of their inefficient exosome incorporation. The production of immunogenic exosomes in the DNA-injected mice was formally demonstrated by the E7-specific $\mathrm{CD}^{+} \mathrm{T}$-cell immune response we detected in mice inoculated with exosomes isolated from plasma of mice inoculated with the Nef ${ }^{\mathrm{mut}} / \mathrm{E} 7$ vector. Finally, we provide evidence that the injection of $\mathrm{Nef}^{\mathrm{mut}} / \mathrm{E} 7 \mathrm{DNA}$ led to the generation of effective antigen-specific cytotoxic $\mathrm{T}$ lymphocytes whose activity was likely part of the potent, therapeutic antitumor effect we observed in mice implanted with TC-1 tumor cells. In summary, we established a novel method to generate immunogenic exosomes in vivo by the intramuscular inoculation of DNA vectors expressing the exosome-anchoring protein $\mathrm{Nef}^{\mathrm{mut}}$ and its derivatives.
\end{abstract}

Keywords: nanovesicles, cytotoxic T lymphocytes, HIV-1 Nef, DNA vectors

\section{Introduction}

Exosomes are vesicles ranging 50-150 $\mathrm{nm}$ and are released constitutively by all cell types. ${ }^{1}$ They are generated by inward invagination of endosome membranes. These intraluminal vesicles form the multivesicular bodies (MVBs) which can traffic to the plasma membrane to which they fuse, thereby releasing their vesicular contents in the extracellular milieu. Exosomes are part of the intercellular communication network. They incorporate messenger RNAs, microRNAs, DNA, and proteins which can be functional in target cells. Nanovesicles showing both physical and biochemical features resembling exosomes, but those generated through direct extrusion of plasma membrane have also been described in muscle cells. ${ }^{2-4}$
Correspondence: Maurizio Federico National AIDS Center, Istituto Superiore di Sanità, Viale Regina Elena, 299, 0016I Rome, Italy

Tel +390649903605

Fax +390649903002

Email maurizio.federico@iss.it 
The exosome immunogenicity basically relies on the amounts and quality of antigens they incorporate. Exosomes were tested as antitumor immunostimulatory agents, and clinical trials demonstrated that they are well tolerated as cell-free vaccines. ${ }^{5,6}$ However, their therapeutic efficacy appeared quite limited, posing the need of new methods to increase their immunogenicity. This issue has been addressed through in vitro methods devoted to engineer foreign antigens to increase their display on the exosome membrane., ${ }^{7,8}$

Exosome biogenesis and HIV budding share the functions of a number of cell proteins including Alix, Tsg101, and several components of the endosomal sorting complex required for transport. ${ }^{9}$ The convergence of exosome and HIV biogenesis implies the possibility that viral products incorporate in exosomes. Such is the case for HIV-1 Nef, which associates with exosomes through anchoring its N-terminal myristoylation to lipid raft microdomains at the endosome membranes. ${ }^{10}$ Nef is a 27 kilodalton $(\mathrm{kDa})$ protein lacking enzymatic activities. However, it can act as a scaffold/adaptor element to trigger activation of signal transducing molecules. ${ }^{11}$

We previously identified a ${ }^{\mathrm{G}} 3^{\mathrm{C}} \mathrm{V} 153^{\mathrm{L}} \mathrm{E} 177^{\mathrm{G}}$ Nef mutant incorporating in exosomes at quite high levels. ${ }^{12}$ This Nef mutant (referred to as $\mathrm{Nef}^{\text {mut}}$ ) is defective for basically all Nef functions. Its efficiency of incorporation in nanovesicles does not change significantly when fused at its C-terminus with foreign proteins. Manipulating $\mathrm{Nef}^{\text {mut }}$ allows the incorporation of high amounts of antigens of choice into exosomes, which thus remain protected from external neutralization/degradation factors. We recently reported that the inoculation in mice of exosomes carrying HPV E7 fused with $\mathrm{Nef}^{\text {mut }}$ induces an effective E7-specific $\mathrm{CD}^{+}$ T cytotoxic lymphocyte (CTL) response. ${ }^{13}$ This result demonstrates that, through the $\mathrm{Nef}^{\text {mut }}$-based engineering strategy, the already proven poor CTL immunogenicity of exosomes can be overcome. However, this strategy would face possible difficulties in view of potential clinical applications, including in areas of standardization of industrial manufacturing, high cost-effectiveness, and storage of the immunogen. For these reasons, we conceived a still unproven, exosomebased vaccine strategy relying on delivery of DNA vectors expressing Nef ${ }^{\text {mut }}$-based fusion proteins into host animal by intramuscular (IM) inoculation. This strategy relies on the very recent observation that muscle cells also, both proliferating and differentiated, constitutively release exosome-like vesicles. Considering that $\mathrm{Nef}^{\text {mut }}$ and derivatives thereof associate with exosomes with high efficiency, we predicted

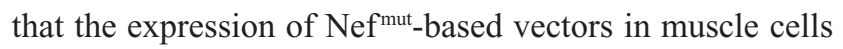

would be sufficient to create a continuous source of engineered, immunogenic exosomes.

Here, we demonstrate that IM inoculation of mice with a DNA vector expressing $\mathrm{Nef}^{\mathrm{mut} / \mathrm{E} 7}$ elicits a potent CTL immune response, thereby blocking the growth of already implanted tumor cells. We provide evidence that the production of endogenously engineered exosomes was the basis of the observed antitumor effect.

\section{Materials and methods Molecular constructs and cell cultures}

All molecular constructs were based on IE-CMV-promoted vectors. Vectors expressing $\mathrm{Nef}^{\mathrm{mut}}, \mathrm{Nef}^{\mathrm{mut}}$ /green fluorescent protein (GFP), ${ }^{12} \mathrm{Nef}_{\mathrm{G} 2 \mathrm{~A}} / \mathrm{GFP},{ }^{14}$ wild-type (wt) Nef, ${ }^{15}$ and HPV E7 ${ }^{16}$ have already been described. 293T, murine muscle $\mathrm{C}_{2} \mathrm{C}_{12}$ (both obtained from American Type Culture Collection, ATCC), and HPV E7-expressing TC-1 tumor cells (a kind gift from Dr Wu, John Hopkins Medical Institutes, Baltimore, MD, USA) were grown in Dulbecco's Modified Eagle's Medium plus 10\% heat-inactivated fetal calf serum (FCS). Transfection assays were carried out by the Lipofectamine 2000-based method (Invitrogen, Thero Fisher Scientific, Waltham, MA, USA), which in the case of $\mathrm{C}_{2} \mathrm{C}_{12}$ cells was modified by adding liposomes to freshly trypsinized cells. Both EL-4 cells ${ }^{17}$ (obtained from ATCC) and mouse splenocytes were cultivated in Roswell Park Memorial Institute 1640 (RPMI) medium plus $10 \%$ FCS.

\section{Exosome isolation, detection, and characterization}

Exosomes were isolated from cell supernatants through differential centrifugations as previously described. ${ }^{18}$ The recovery of exosomes from the plasma of inoculated mice was carried out in a similar way except that samples were fivefold diluted before starting centrifugations. The amounts of recovered exosomes were evaluated by measuring the activity of acetylcholinesterase (AchE), ie, a classical exosome marker, ${ }^{19}$ through the use of the Amplex Red kit (Molecular Probes, Thermo Fisher) following the manufacturer's recommendations. The AchE activity was measured in $\mathrm{mU} / \mathrm{mL}$, where $1 \mathrm{mU}$ is defined as the amount of enzyme which hydrolyzes 1 pmole of acetylcholine to choline and acetate per minute at $\mathrm{pH} 8.0$ at $37^{\circ} \mathrm{C}$.

Fluorescent exosomes from transfected cell cultures were either directly detected by fluorescence-activated cell sorting (FACS, Gallios, Beckman Coulter, Brea, CA, USA), or, in the case of exosomes isolated from plasma, analyzed upon 
binding with aldehyde/sulfate latex beads (Molecular Probes, Thermo Fisher). To this end, samples were incubated with $5 \mu \mathrm{L}$ of beads overnight at room temperature on a rotating plate, washed, and incubated for 1 hour at $4^{\circ} \mathrm{C}$ with either anti-CD63 mAb MX-49.129.5 from Abcam (Cambridge, UK) or a control isotype. The incubation was then repeated using secondary PE-conjugated Abs. Finally, beads were resuspended in $1 \times \mathrm{PBS}-2 \% \mathrm{v} / \mathrm{v}$ formaldehyde and analyzed with FACS.

Western blot analyses of both cell lysates and exosomes were carried out as described previously. ${ }^{12}$ Filters were revealed using 1:1,000 diluted sheep anti-Nef antiserum ARP 444 (a generous gift of M Harris, University of Leeds, Leeds, UK), 1:250 diluted anti- $\beta$ actin AC-74 mAb from Sigma (Milan, Italy), and 1:100 diluted anti-Alix H-270 polyclonal Abs from Santa Cruz (Heidelberg, Germany).

\section{Mice immunization and detection of IFN- $\gamma$-producing CD8 ${ }^{+} \mathrm{T}$ lymphocytes}

All studies with animals described here have been approved by the Ethical Committee of the Istituto Superiore di Sanità, Rome, Italy (protocol number 555/SA/2012) according to Legislative Decree 116/92, which has implemented in Italy the European Directive 86/609/EEC on laboratory animal protection. Animals used in our research have been housed and treated according to the guidelines mentioned in the Legislative Decree. C57 Bl/6 mice were purchased from Charles River Laboratories Italia (Calco, Italy) and inoculated IM two times at 10 day intervals with $50 \mu \mathrm{g}$ in each quadriceps with plasmid DNA purified with endotoxin-free Qiagen kit (Hilden, Germany). Mice were also inoculated subcutaneously (SC) three times at ten day intervals with exosomes (6 mU AchE equivalents) purified from plasma of DNA injected mice, and sacrificed 10 days after the last immunization. To detect both E7- and Nef-specific $\mathrm{CD}^{+} \mathrm{T}$-cell immune responses, splenocytes were put in IFN- $\gamma$ Elispot microwells (Millipore, Billerica, MA) in the presence of $5 \mu \mathrm{g} / \mathrm{mL}$ of either HPV E7 or HIV-1 Nef 8- or 9-mer peptides binding the $\mathrm{H}-2 \mathrm{~K}^{\mathrm{b}}$ complex of $\mathrm{C} 57$ Bl/6 mice, ie, DLYCYEQL (aa 21-28) and RAHYNIVTF (aa 49-57) for E7, ${ }^{20}$ and TAATNADCA (aa 48-56) for Nef. ${ }^{21}$ H-2 $\mathrm{K}^{\mathrm{b}}$ binding HPV E6-specific KLPQLCTEL (aa 18-26) and YDFAFRDL (aa 50-57) peptides ${ }^{20}$ were used as unrelated peptides. After overnight incubation, IFN- $\gamma$ Elispot plates were developed (Mabtech AB, Nacka Strand, Sweden) and spot-forming units were counted using an Elispot reader (A.EL.VIS. Elispot reader and Analysis software $\mathrm{GmbH}$, Turin, Italy).

\section{Fluorescence microscope analysis}

Slices $(7 \mu \mathrm{m})$ from quadriceps of inoculated mice were prepared using a cryostat (Leika CM 3050, Wetzlar, Germany) and placed to slides. The slices were then incubated with 4',6'-diamidino-2-phenylindole (DAPI; Vector Laboratories, Peterborough, UK) together with an antifade mounting medium. Finally, coverslips were mounted on the slides, which were then observed with a Zeiss Axioskop 2 Plus (Oberkochen, Germany) fluorescence microscope.

\section{CTL assay}

$\mathrm{CD}^{+} \mathrm{T}$-cells were isolated from splenocytes by positive immunomagnetic selection (Miltenyi Biotec Gmbh, Teterow, Germany). They were put in coculture for 6 hours in RPMI $10 \%$ FCS with EL-4 cells previously labeled with carboxyfluorescein succinimidyl ester (CFSE; Invitrogen, Thermo Fisher), following the manufacturer's recommendation, and treated overnight with either E7 or unrelated peptides. The cocultures were run at different cell ratios (ie, 20:1, 10:1, and 5:1 effector/target cells) in $200 \mu \mathrm{L}$ of RPMI $20 \%$ in U-bottom 96 well plates. Afterward, EL-4 cell mortality was scored by FACS analysis soon after addition of 7-AAD at final concentration of $1 \mu \mathrm{g} / \mathrm{mL}$.

\section{Detection of anti-E7 and anti-Nef antibodies in plasma}

Plasma from inoculated mice were pooled, and twofold serial dilutions starting from 1:10 were assayed for the presence of both E7- and Nef-specific Abs as previously described. ${ }^{22}$ The end-point dilution corresponded to a $<0.1$ OD absorbance at $450 \mathrm{~nm}$. Each plasma sample was assayed in triplicate, and the mean of the absorbance values was taken as final readout.

\section{Antitumor effects of Nefmut/E7-expressing vector}

The antitumor activity was evaluated in mice previously challenged with $2 \times 10^{5}$ TC- 1 cells. DNA inoculations were performed 4 and 11 days after tumor cell challenge following the above reported protocol, and only in mice that developed palpable tumors. Tumor growth was monitored by visual inspection, palpation, and measurement of tumor nodule diameter calculated as $\left(\right.$ length $\times$ width $\left.^{2}\right) / 2$. At the end of the observation time, tumors were explanted and weighted.

\section{Statistical analysis}

When appropriate, data are presented as mean + standard deviation. In some instances, the paired Student's $t$-test was 
used and confirmed using the nonparametric Wilcoxon rank sum test. $P<0.05$ was considered significant.

\section{Results}

Detection of engineered exosomes released by DNA-transfected murine muscle cells

We preliminarily investigated whether, as already assessed in different human cell types, the expression of a Nef ${ }^{\text {mut }}$ expressing DNA vector in murine muscle cells was sufficient to generate engineered exosomes. For the sake of clarity, exosome-like nanovesicles released by murine muscle cells are here defined as exosomes, although their biogenesis somehow differs from that of MVB-generated exosomes. ${ }^{2}$

Murine muscle $\mathrm{C}_{2} \mathrm{C}_{12}$ and, as control, human 293T cells were transfected with vector expressing GFP fused at the C-terminus of either $\mathrm{Nef}^{\text {mut }}$ or a Nef isotype inefficiently associating with exosomes (ie, $\left.\mathrm{Nef}_{\mathrm{G} 2 \mathrm{~A}}\right){ }^{23}$ Transfected cells were monitored for the respective efficiency of transfection (Figure 1A), which in muscle cells appeared to be over $50 \%$. The supernatants were collected, and exosomes isolated through differential centrifugation. Exosome preparations were then titrated in terms of AchE activity. The two cell types produced apparently similar levels of AchE-positive
A
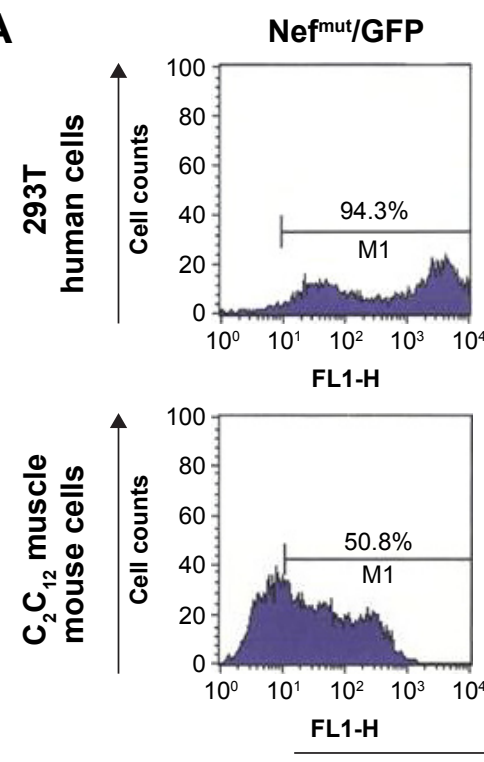

C
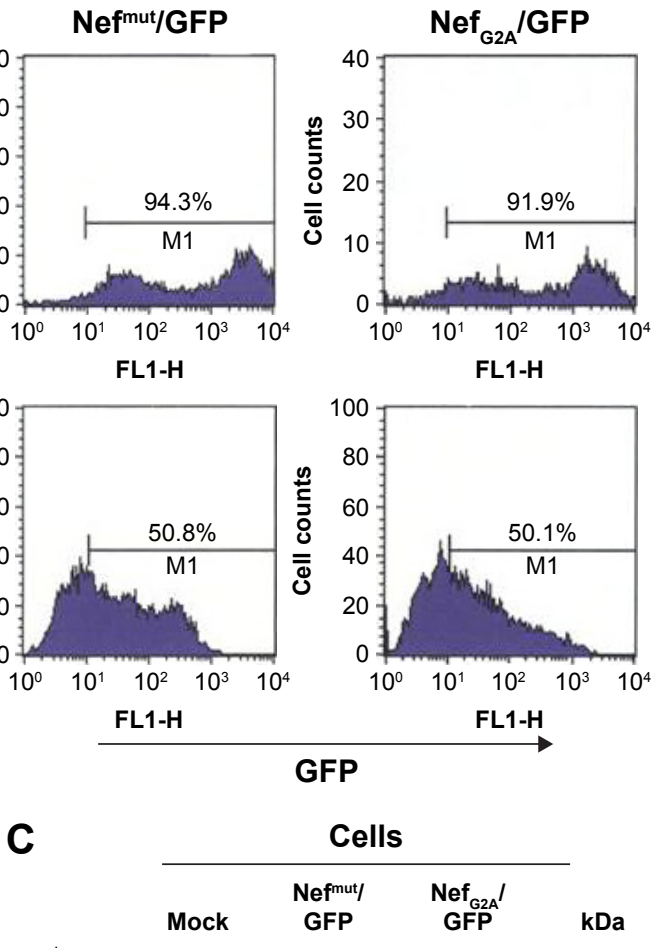

B

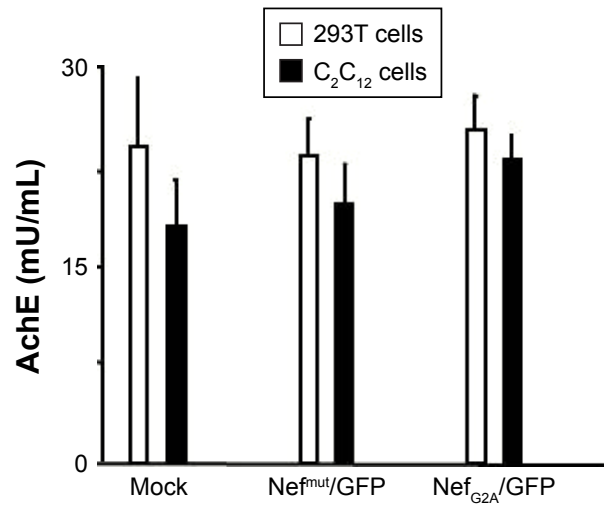

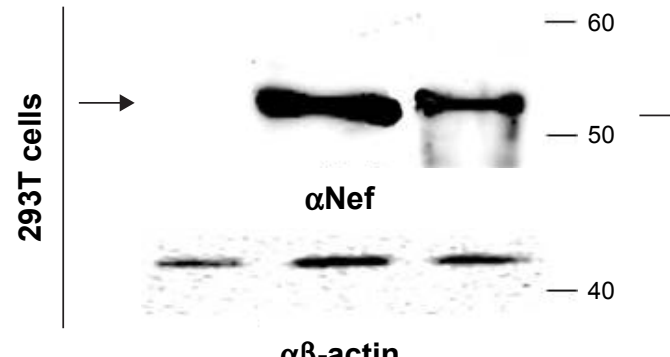

Exosomes
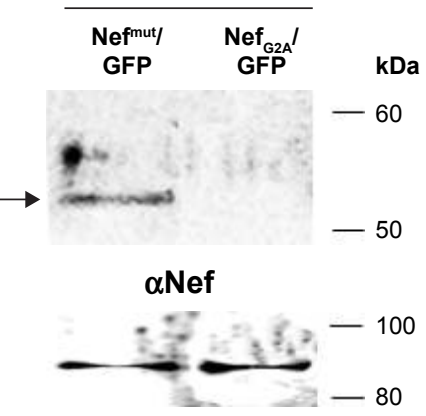

$\alpha \beta$-actin

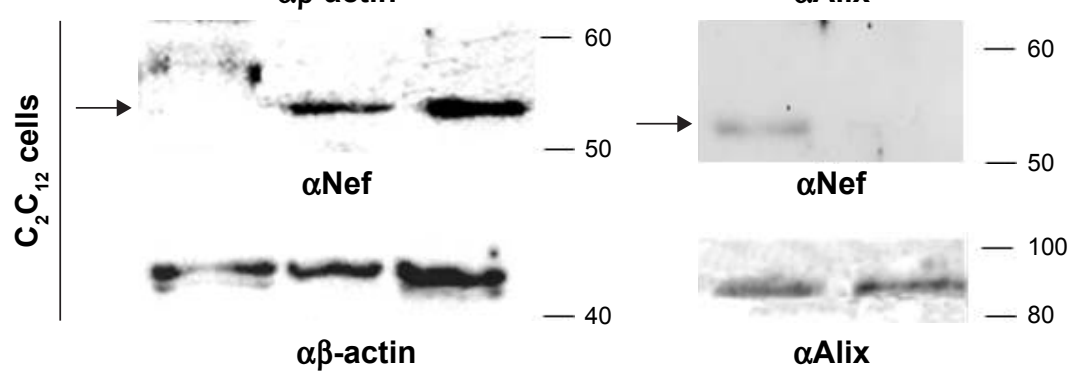

Figure I (Continued) 


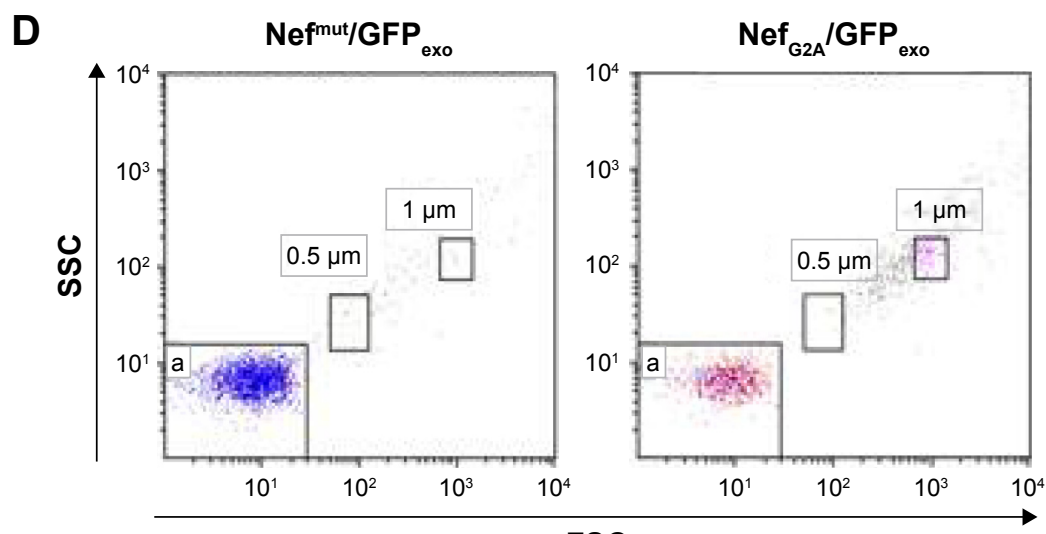

\section{FSC}

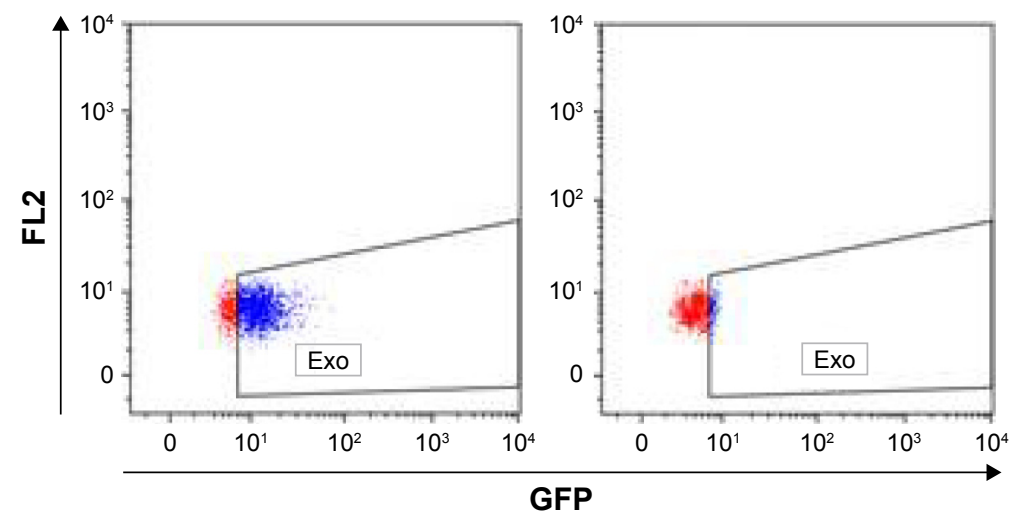

Figure I Detection of engineered exosomes in supernatants of transfected murine muscle cells.

Notes: (A) FACS analysis of both human 293T and murine $C_{2} C_{12}$ muscle cells 2 days after transfection with either Nefmut/GFP- or Nef ${ }_{\text {G2A }} /$ GFP-expressing vectors. MI marks the range of positivity as established by the analysis of mock-transfected cells. Percentages of positive cells are reported. (B) Quantification in terms of AchE activity of exosome preparations recovered by differential centrifugations of supernatants from the same number (ie, $5 \times 10^{6}$ ) of both $293 \mathrm{~T}$ and $\mathrm{C}_{2} \mathrm{C}_{12}$ transfected cells. (C) Western blot analysis of exosomes from both $293 \mathrm{~T}$ and $\mathrm{C}_{2} \mathrm{C}_{12}$ transfected cells. Nef-based products were detected in both cell lysates and exosomes, while $\beta$-actin and Alix served as markers for cell lysates and exosomes, respectively. Arrows mark the relevant protein products. Molecular markers are given in kDa. (D) FACS analysis of exosomes from $\mathrm{C}_{2} \mathrm{C}_{12}$ transfected cells. Ten $\mathrm{mU}$ of exosomes from $\mathrm{C}_{2} \mathrm{C}_{12}$ cells transfected with either Nef ${ }^{\text {mut/GFP- or }} \mathrm{Nef}_{\text {G2A }} / \mathrm{GFP}$-expressing vectors were analyzed in terms of both FSC and SSC (top panels), as well as GFP fluorescence (bottom panels). Quadrants indicate the dimension of the detected particulate (top panels, a: $0.1 \mu \mathrm{m}$ ) and the range of positivity as calculated by the analysis of exosomes from mock-transfected cells (bottom panels). Results are representative of two independent experiments.

Abbreviations: AchE, acetylcholineesterase; exo, exosomes; FACS, fluorescence-activated cell sorting; FL2, fluorescence channel 2; FSC, forward scatter; GFP, green fluorescent protein; SSC, side scatter.

nanovesicles whatever the transfection conditions (Figure 1B). The western blot analysis of $100 \mu \mathrm{U}$ equivalent of exosomes showed the presence of Nef-derived molecules in exosomes from both $293 \mathrm{~T}$ and $\mathrm{C}_{2} \mathrm{C}_{12}$ cells transfected with $\mathrm{Nef}^{\text {mut/ }}$ GFP but not $\mathrm{Nef}_{\text {G2A }} / \mathrm{GFP}$ vectors (Figure 1C). The FACS analysis confirmed the association of fluorescence with the nanovesicles we recovered from $\mathrm{C}_{2} \mathrm{C}_{12}$ cells transfected with

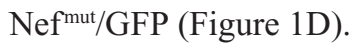

In sum, we have proven that exosome-like nanovesicles released by murine muscle cells can be engineered by $\mathrm{Nef}^{\text {mut }}$ derivatives as previously proven in epithelial-like, human 293 T cells.

\section{Nef ${ }^{\text {mut }}$-derived products can be detected in exosomes from plasma of DNA- inoculated mice}

To assess whether engineered exosomes can be generated in vivo, $50 \mu \mathrm{g}$ of either $\mathrm{Nef}^{\mathrm{mut}} / \mathrm{GFP}, \mathrm{Nef}_{\mathrm{G} 2 \mathrm{~A}} / \mathrm{GFP}$, or empty vector were inoculated in each quadriceps of $\mathrm{C} 57 \mathrm{Bl} / 6$ mice. To assess the expression of injected vectors, 3 days later, slices of muscle tissues obtained from the zones of inoculation were analyzed for the expression of GFP-related products. Consistently with what was already described for wt Nef, ${ }^{24}$ $\mathrm{Nef}^{\text {mut }}$ accumulated at the plasma membrane as well as in an intracellular punctate pattern. Differently, the $\mathrm{Nef}_{\mathrm{G} 2 \mathrm{~A}}$ mutant localized preferentially in the cytoplasm, as a consequence of the lack of N-terminal myristoylation (Figure 2A). Three and nine days after inoculation, plasma from the inoculated mice was recovered and exosomes were isolated by differential centrifugations. Exosome preparations were titrated in terms of AchE activity, equivalent amounts of them were bound to white aldehyde/sulfate latex beads, and finally labeled for the CD63 exosome marker. By FACS analysis of the exosomebead complexes, we detected fluorescent exosomes among those isolated only from the plasma of mice injected with

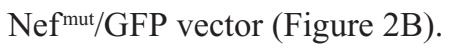


A

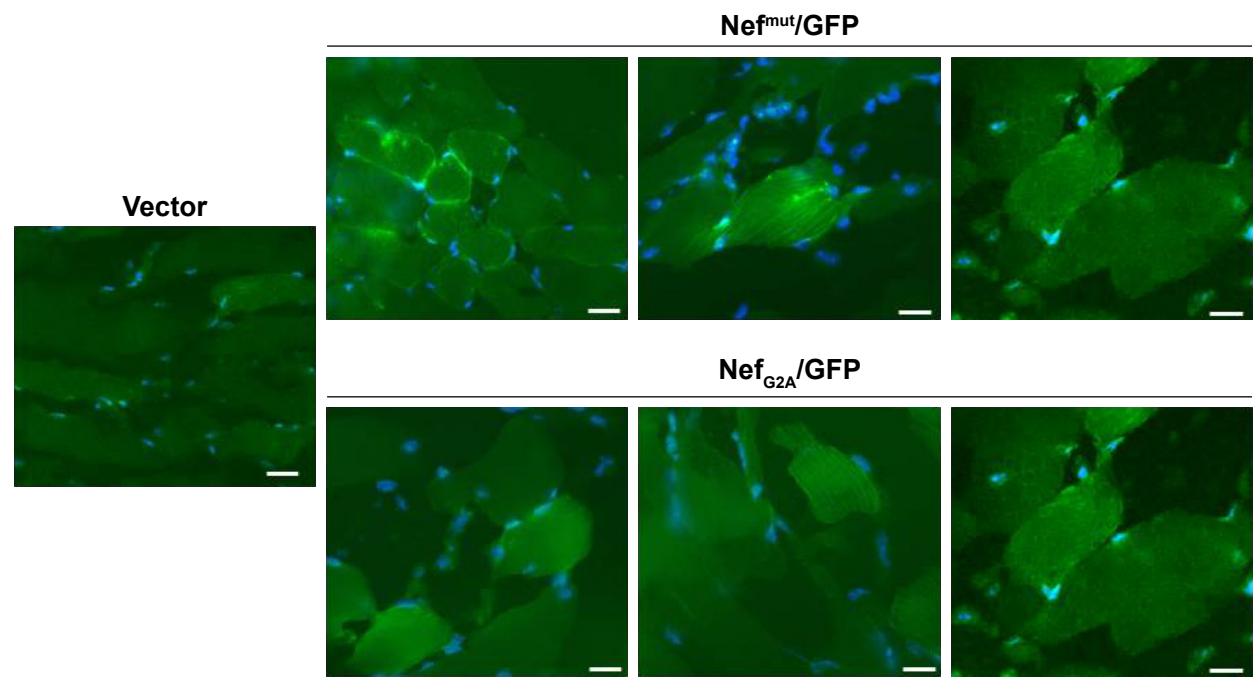

B
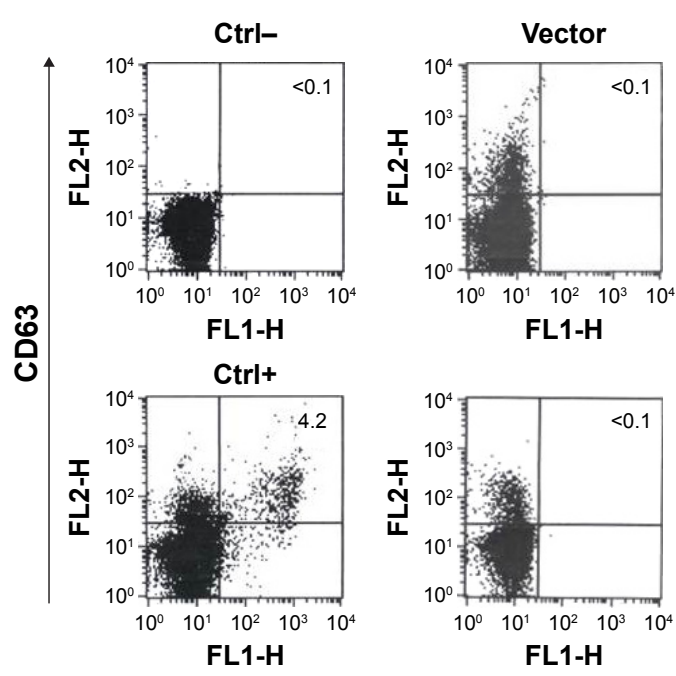

Day 3
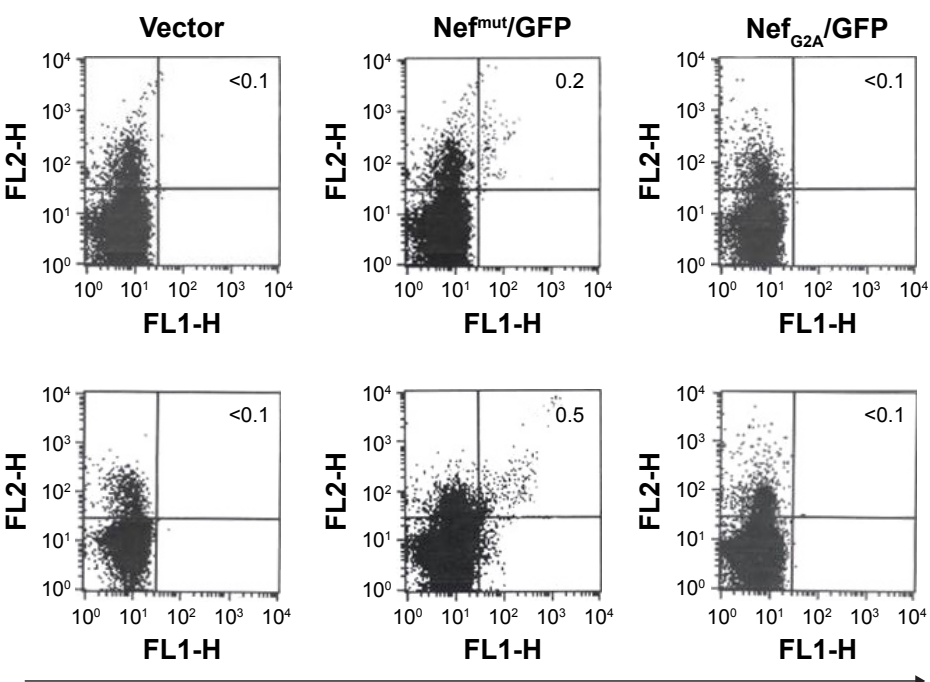

Day 9

\section{GFP}

Figure 2 Detection of fluorescent nanovesicles in plasma from mice inoculated with a Nefmut/GFP-expressing DNA vector.

Notes: (A) Analysis of the expression of GFP-related products in muscle tissues from mice inoculated with the indicated DNA vectors. Samples from different injected mice are represented by each picture. Scale bars: $50 \mu \mathrm{M}$. (B) FACS analysis of exosomes from plasma of C57 BI/6 mice inoculated IM with DNA vectors expressing the indicated products. Three and nine days after injection, exosomes were isolated from the pool of plasma of three injected mice by differential centrifugations. Then, equivalent amounts (ie, I mU) of exosomes were bound to surfactant-free white aldehyde/sulfate latex beads, labeled with anti-CD63 mAb, and finally assayed for their fluorescence. As control, $10 \mu \mathrm{U}$ of exosomes isolated from the supernatants of $\mathrm{C}_{2} \mathrm{C}_{12}$ cells transiently transfected with Nefmut/GFP vector were used (Ctrl+). Quadrants were set on the basis of the fluorescence of beads incubated with anti-CD63 mAb (Ctrl-). Percentages of positive events are indicated. Results are representative of two assays.

Abbreviations: FACS, fluorescence-activated cell sorting; GFP, green fluorescent protein; IM, intramuscular.

These results indicated that the inoculation in mice of vectors expressing $\mathrm{Nef}^{\mathrm{mut}}$ derivatives can lead to the generation of engineered exosomes.

\section{HPV E7-specific CTL response induced by IM inoculation of Nef ${ }^{\text {mut} / E 7-e x p r e s s i n g ~}$ DNA vector}

Next, we evaluated the immunogenicity of DNA vectors expressing $\mathrm{Nef}^{\mathrm{mut}}$ derivatives. C57 Bl/6 mice (six per group) were inoculated IM in each quadriceps with $50 \mu \mathrm{g}$ of vectors expressing either $\mathrm{Nef}^{\mathrm{mut}} / \mathrm{E} 7$ or E7 alone or empty vector. Since we previously noticed that $\mathrm{E} 7$ associates with exosomes at undetectable levels (not shown), the inclusion of a vector expressing E7 alone was instrumental to evaluate the benefit of the $\mathrm{Nef}^{\text {mut }}$ fusion in terms of CD $8^{+} \mathrm{T}$-cell immunogenicity. The inoculations were repeated 10 days later, and after additional 10 days mice were sacrificed. Then, the splenocytes were isolated and cultured overnight in IFN- $\gamma$ Elispot 
microwells in the presence of either unrelated, Nef-, or E7-specific nonamers. The $\mathrm{CD} 8^{+} \mathrm{T}$-cell activation observed in cultures with unrelated peptides remained at background levels as in the case of splenocytes cultured in the absence of peptides (not shown). On the other hand, peptide-specific cell activation was clearly detectable in splenocytes from mice inoculated with $\mathrm{Nef}^{\mathrm{mut}} / \mathrm{E} 7$-expressing vector (Figure 3A). Conversely, no $\mathrm{CD}^{+} \mathrm{T}$-cell response was observed in cultures of splenocytes from mice receiving either E7-expressing or empty vector, whatever the peptide used. Notably, anti-E7 antibodies were detected only in plasma from mice inoculated with the vector expressing E7 alone (Figure 3B).

To evaluate whether the $\mathrm{CD} 8^{+} \mathrm{T}$-cell response coupled with an E7-specific CTL activity, $\mathrm{CD}^{+} \mathrm{T}$-cells were isolated from pools of splenocytes and then put in coculture for 6 hours at different cell ratios with CFSE-labeled EL-4 cells pretreated overnight with either unrelated or E7 nonamers. Afterward, the cocultures were labeled with 7-AAD and percentages of dead target cells were scored by FACS analysis. The results reported in Figure 3C show a clear increase of target cell mortality in both 20:1 and 10:1 cocultures comprising $\mathrm{CD}^{+} \mathrm{T}$ lymphocytes from mice inoculated with the Nef ${ }^{\text {nut }}$ E7-expressing vector and EL-4 pretreated with E7-specific nonamers. This result demonstrates the presence of E7-specific CTLs among the $\mathrm{CD}^{+} \mathrm{T}$ lymphocytes isolated from mice inoculated with the $\mathrm{Nef}^{\text {mut/ }}$ E7-expressing vector.

Taken together, these data indicated that IM inoculation of a vector expressing a heterologous antigen fused with $\mathrm{Nef}^{\text {mut }}$ leads to the induction of a strong antigen-specific CTL response in the absence of antibody production.

\section{Lack of immunogenicity of a DNA vector expressing the wt Nef isoform}

To support the idea that high levels of $\mathrm{Nef}^{\text {mut }}$ incorporation in exosomes were mandatory to elicit the antigen-specific $\mathrm{CD}^{+} \mathrm{T}$-cell response, we reproduced the immunogenicity experiments by inoculating mice with vectors expressing the wt isoform of Nef, which is known to incorporate in exosomes at much lower extents compared to $\mathrm{Nef}^{\text {mut }}{ }^{12}$ To this end, $\mathrm{C} 57 \mathrm{Bl} / 6$ mice (four per group) were injected IM in each quadriceps with $50 \mu \mathrm{g}$ of a vector expressing either wt Nef or $\mathrm{Nef}^{\mathrm{mut}}$ or with the empty vector. The inoculations were repeated 10 days later, and after an additional 10 days the mice were sacrificed. Splenocytes were then isolated and cultured overnight in IFN- $\gamma$ Elispot microwells in the presence of either unrelated or Nef nonamers. As shown in Figure 4, mice inoculated with the vector expressing wt
Nef, differently to those receiving the $\mathrm{Nef}^{\text {mut }}$ vector, failed to develop a detectable Nef-specific $\mathrm{CD}^{+} \mathrm{T}$ cell response.

This result indicates that the levels of antigen incorporation into exosomes are critical for the immune response, meanwhile suggesting that the functions of wt Nef were not per se involved in the antigen-specific $\mathrm{CD} 8^{+} \mathrm{T}$-cell activation.

\section{Immunogenicity of exosomes isolated from plasma of mice immunized with Nefmut/E7 DNA}

To enforce the hypothesis that the $\mathrm{CD}^{+} \mathrm{T}$-cell immune response we detected upon inoculation of $\mathrm{Nef}^{\text {mut }}$-expressing vectors relied on production of engineered exosomes, we next tested whether exosomes purified from plasma of DNAinoculated mice were immunogenic in recipient-naïve mice. For this, eight mice were inoculated with vectors expressing E7, Nef ${ }^{\mathrm{mut}} / \mathrm{E} 7$, or empty vector following the schedule mentioned earlier. Eight days after the last immunization, peripheral blood mononuclear cells were recovered through retro-orbital bleeding and checked for the E7-specific CD8 ${ }^{+}$ T-cell response. As already observed, the injection of the

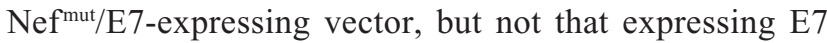
alone, gave rise to a well detectable E7-specific $\mathrm{CD}^{+} \mathrm{T}$-cell response (Figure 5A). Plasma from the different mouse groups were pooled and exosomes were isolated by differential centrifugation. Afterward, exosomes were titrated in terms of AchE activity, and $6 \mathrm{mU}$ AchE equivalents were injected SC in syngeneic mice three times at 10 day intervals. Finally, mice were sacrificed, and splenocytes tested for the E7-specific $\mathrm{CD}^{+} \mathrm{T}$-cell responses, which were noticed only in splenocyte cultures from mice inoculated with exosomes purified from mice injected with the Nef ${ }^{\text {mut}} / E 7$ DNA vector (Figure 5B).

These results indicate that the IM injection of DNA expressing Nef ${ }^{\text {mut}} / \mathrm{E} 7$ leads to the production of immunogenic exosomes, hence further supporting the idea that the production of endogenously engineered exosomes was on the basis of the strong E7-specific $\mathrm{CD}^{+} \mathrm{T}$-cell immune response observed in the DNA-injected mice.

\section{Antitumor therapeutic effect of IM inoculation of Nefmut/E7-expressing DNA vector}

Finally, we evaluated the potency of the $\mathrm{CD}^{+} \mathrm{T}$-cell immune

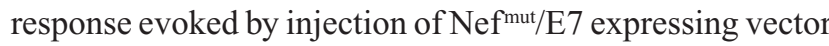
in terms of antitumor effect. To this end, we set up therapeutic 

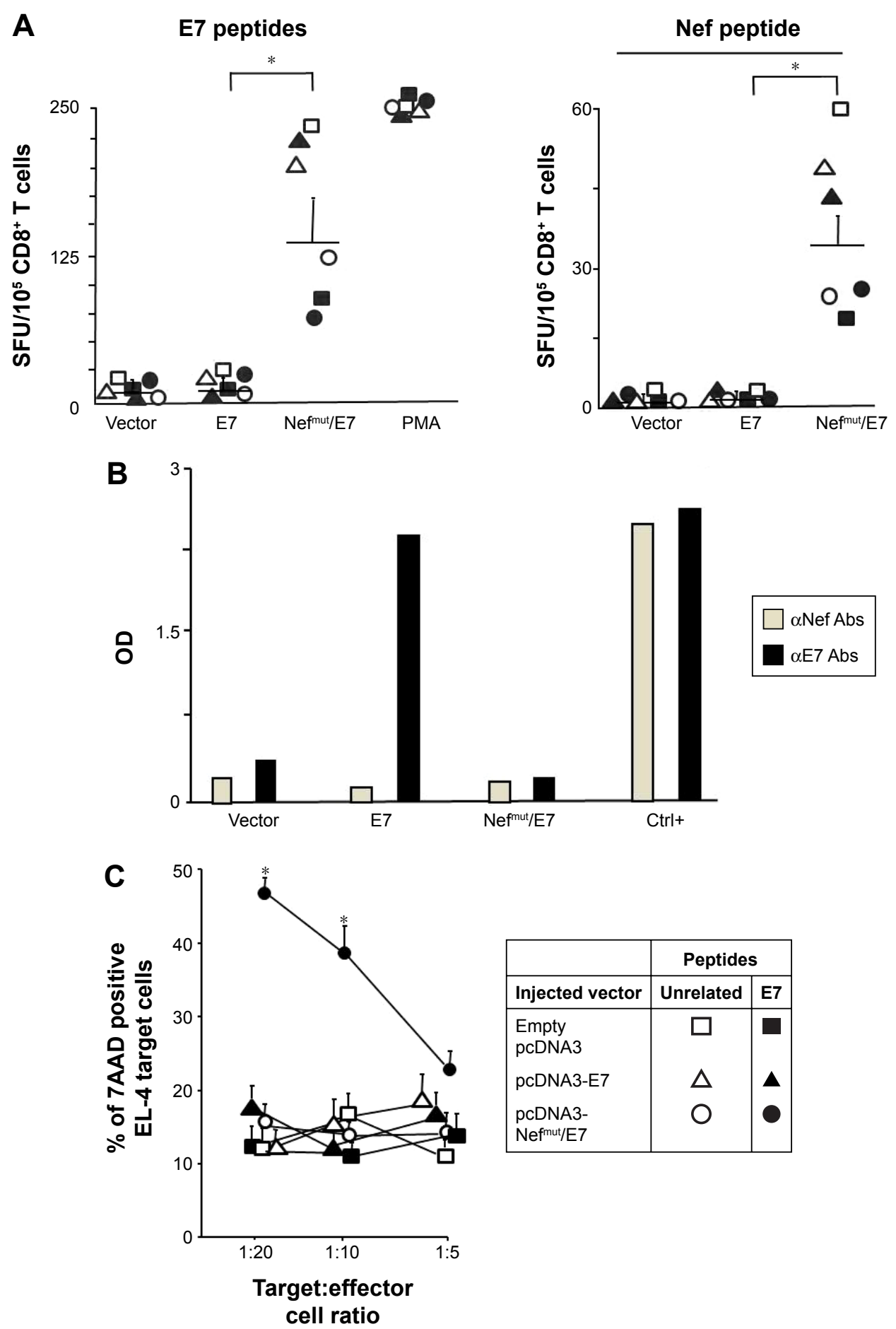

\begin{tabular}{|l|c|c|}
\hline & \multicolumn{2}{|c|}{ Peptides } \\
\hline Injected vector & Unrelated & E7 \\
\hline Empty & $\square$ & \\
pcDNA3 & & \\
pcDNA3-E7 & $\Delta$ & $\mathbf{\Delta}$ \\
pcDNA3- & $\bigcirc$ & 0 \\
Nef ${ }^{\text {mut/E7 }}$ & & \\
\hline
\end{tabular}

Figure 3 The inoculation of Nef ${ }^{\text {mut/E7 DNA vector induces an E7-specific CD8 }}{ }^{+}$T-cell immune response in the absence of antibody production.

Notes: $(\mathbf{A}) \mathrm{CD}^{+}$T-cell immune response in mice inoculated with DNA vectors expressing either E7, Nefmut/E7, or empty vector. C57 BI/6 mice (six per group) were inoculated two times with the different DNA vectors. At the time of sacrifice, $10^{5}$ splenocytes were incubated overnight with or without $5 \mu g / \mathrm{mL}$ of either unrelated (not shown) E7- or Nef-specific nonamers in triplicate IFN- $\gamma$ Elispot microwells. As control, cells were incubated with $5 \mathrm{ng} / \mathrm{mL}$ of PMA plus $500 \mathrm{ng} / \mathrm{mL}$ of ionomycin. Shown are the number of IFN- $\gamma \mathrm{SFU} / 10^{5}$. Intergroup mean $+\mathrm{SD}$ of SFU are also reported. The results are representative of three independent experiments. $* P<0.05$. (B) Anti-Nef and anti-E7 antibody detection in I:I0 diluted plasma from mice inoculated with the indicated DNA vectors. As internal positive control standard (Ctrl+), I:I0,000 dilutions of plasma from mice injected with $10 \mu \mathrm{g}$ of either recombinant E7 or Nef proteins plus adjuvant were used. Shown are the mean absorbance values of triplicates of plasma pooled from six mice per group. (C) CTL assay carried out with CD8 ${ }^{+} \mathrm{T}$-cells from mice inoculated with the indicated vectors. CD8 ${ }^{+} \mathrm{T}$-cells were isolated from pooled splenocytes, cultured in duplicate for 6 hours at 20:I, 10:I, and 5:I cell ratios with EL-4 cells previously labeled with CFSE, and treated with either unrelated or E7 peptides for 16 hours. Six hours later, EL-4 cell mortality was scored by FACS analysis upon 7-AAD labeling. Shown are the mean values + SD as calculated from four independent experiments. $* p<0.05$.

Abbreviations: CTL, cytotoxic T lymphocyte; FACS, fluorescence-activated cell sorting; OD, optical density; PMA, phorbol I2-myristate I3-acetate; SFU, spot-forming unit. 


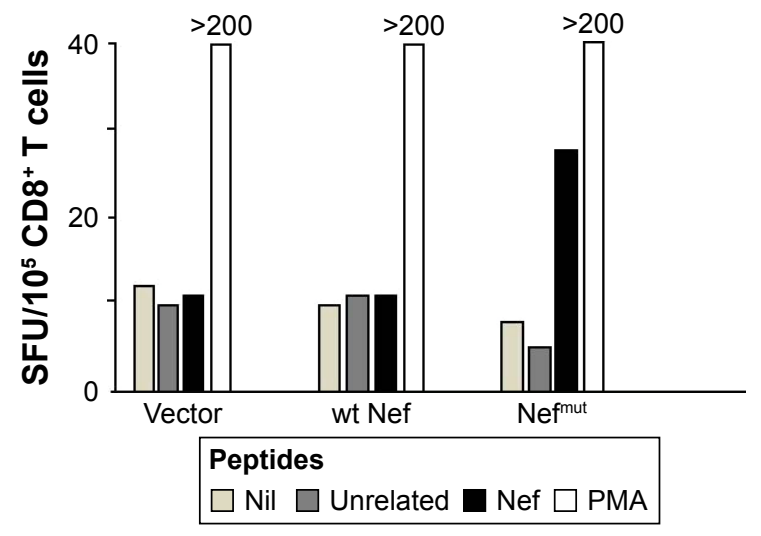

Figure 4 Injection in mice of wt Nef-expressing DNA vector fails to elicit Nefspecific CD8 ${ }^{+} \mathrm{T}$-cell immune response.

Notes: C57 Bl/6 mice (four per group) were inoculated intramuscularly two times with DNA vectors expressing wt Nef, Nefmut, or empty vector, and sacrificed 10 days after the last immunization. Splenocytes were then cultured overnight in triplicate in IFN- $\gamma$ Elispot microwells in the absence or presence of either unrelated or Nef-specific nonamers. As control, cells were incubated with $5 \mathrm{ng} / \mathrm{mL}$ of PMA and $500 \mathrm{ng} / \mathrm{mL}$ of ionomycin. Shown are the mean of SFU/I $0^{5}$ cells from a representative of two independent experiments.

Abbreviations: PMA, phorbol I2-myristate 13-acetate; SFU, spot-forming unit; wt, wild type.

immunization assays on $\mathrm{C} 57 \mathrm{Bl} / 6$ mice inoculated $\mathrm{SC}$ with $2 \times 10^{5}$ TC- 1 cells. Mice developing a tumor mass detectable by palpation, ie, of about $2 \mathrm{~mm}$ diameter, were then inoculated with $50 \mu \mathrm{g} /$ quadriceps of vectors expressing either empty vector, $\mathrm{Nef}^{\mathrm{mut}}$ (four mice per each group) or $\mathrm{Nef}^{\mathrm{mut}} / \mathrm{E} 7$ (six mice) at days 4 and 11 after cell implantation. As control, 4 tumor-implanted mice were injected with the vehicle alone. At day 21, retro-orbital bleeding was carried out on mice injected with Nef ${ }^{\text {mut }}$ - or Nef ${ }^{\text {mut} / E 7-e x p r e s s i n g ~ v e c t o r s ~}$ to assess the induction of E7-specific $\mathrm{CD}^{+} \mathrm{T}$-cell immune response (Figure 6A). The growth of tumors was monitored over 30 days, and thereafter mice were sacrificed, tumors explanted, and weighted. Figure 6B shows that, whereas the injection of control DNA vectors did not influence the growth of implanted tumor cells, their expansion was

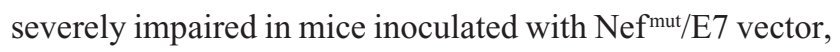
with tumor cells apparently being cleared in three mice, as confirmed by tumor weights (Figure 6C).

Hence, the inoculation of $\mathrm{Nef}^{\mathrm{mut}} / \mathrm{E} 7$-expressing DNA vector elicited a $\mathrm{CD}^{+} \mathrm{T}$-cell immune response also in the presence of tumor cells. Most importantly, this immune response was both strong and rapid enough to inhibit the tumor growth and, in some instances, clear the implanted tumor cells.

Taken together, these results represent a relevant milestone toward possible therapeutic applications of immunization strategies based on $\mathrm{Nef}^{\text {mut }}$-based endogenously engineered exosomes.

\section{Discussion}

We here describe a simple exosome-mediated strategy to induce unrestricted CTL immunity through IM DNA inoculation. Muscle cells constitutively release exosome-like
A

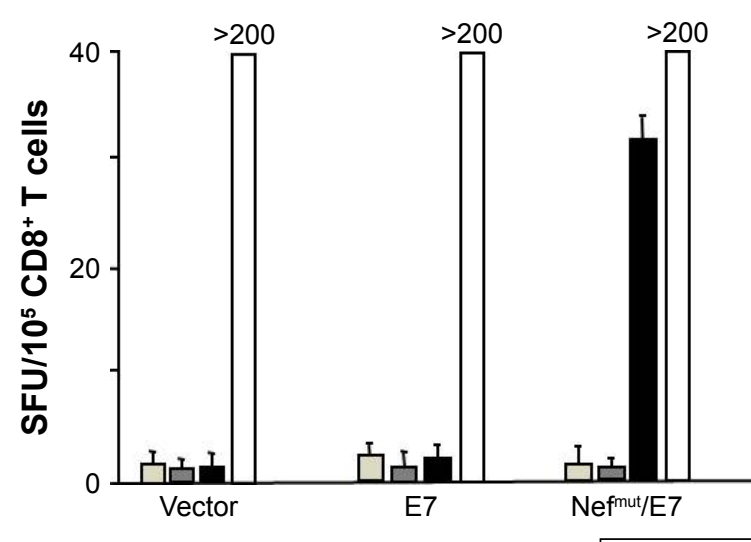

B

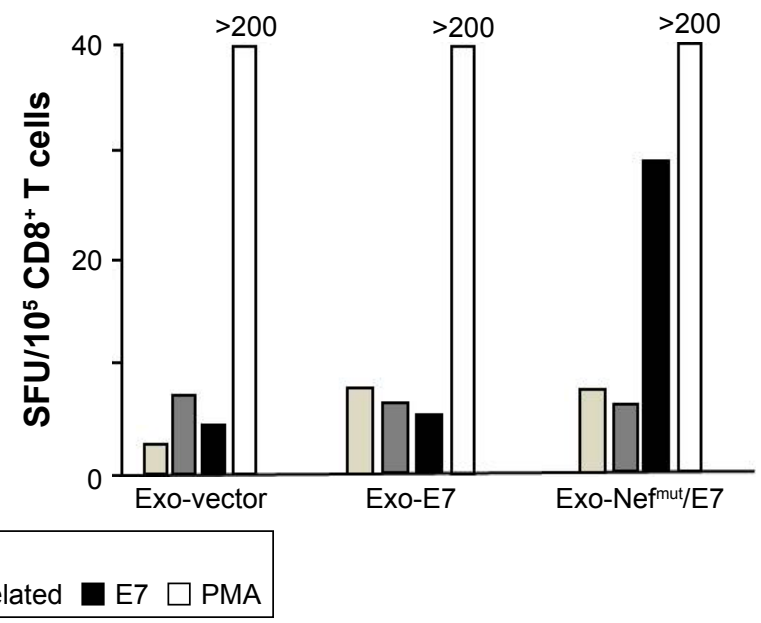

Figure 5 E7-specific CD8 ${ }^{+}$T-cell immunity induced in mice by injection of exosomes from mice inoculated with Nef ${ }^{\text {fut} / E 7 ~ D N A ~ v e c t o r . ~}$

Notes: Donor C57 Bl/6 mice (8 per group) were inoculated two times with the indicated DNA vectors, and 10 days after the last inoculation PBMCs were recovered from retro-orbital bleeding and tested in IFN- $\gamma$ Elispot assay for the presence of E7-specific CD8 ${ }^{+} \mathrm{T}$-cells. In panel $\mathbf{A}$ the mean $+\mathrm{SD}$ of SFU/I0 $0^{5}$ cells as calculated from a representative of 2 experiments are shown. Two days later, the mice were sacrificed and exosomes were isolated from plasma by differential centrifugation. Equivalent amounts of these exosomes were then inoculated in syngeneic mice ( 3 per group) three times. Ten days after the last inoculation splenocytes were tested by IFN- $\gamma$ Elispot assay carried out in triplicate. In panel B the means of SFU/ $/ 0^{5}$ cells as calculated from two independent experiments are shown. PMA: cells incubated with 5 ng/mL PMA and $500 \mathrm{ng} / \mathrm{mL}$ ionomycin.

Abbreviations: PBMCs, peripheral blood mononuclear cells; PMA, phorbol I2-myristate 13-acetate; SD, standard deviation; SFU, spot-forming unit. 
nanovesicles through extrusion of plasma membrane with a biogenesis at least in part different from that of MVB-generated exosomes. Thus, considering that Nef ${ }^{\text {nut }}$ based in vitro engineered exosomes we previously described were generated in epithelial-like human cells, investigating whether and how efficiently the ectopic expression of $\mathrm{Nef}^{\text {fnut }}$ leads to the release of engineered exosomes in murine cells was mandatory. Data we obtained with $\mathrm{C}_{2} \mathrm{C}_{12}$ cells supported the idea that $\mathrm{Nef}^{\text {mut }}$ accumulates into exosome-like nanovesicles released by murine muscle cells at levels similar to those observed in human cells. Our investigations did not include terminally differentiated muscle cells, ie, the cell type most likely targeted by IM inoculation in mice, since we assumed that the cell differentiation does not significantly impact the mechanisms underlying intracellular vesicle trafficking. Since we expected that the majority of muscle cells targeted by IM DNA inoculation was differentiated, the detection of engineered exosomes in plasma from inoculated mice supported the idea that terminally differentiated muscle cells indeed release engineered exosomes in vivo. We cannot exclude that at least part of injected DNA could target other cell types by means, for instance, of the diffusion of DNA in draining lymph nodes, where it can be captured and internalized by dendritic cells (DCs). However, we believe that DCs contribute limitedly to the overall production of engineered exosomes since SC inoculation of Nef ${ }^{\text {mut }} / \mathrm{E} 7$-expressing DNA, which is expected to preferentially target DCs, gave rise to a quite weak E7-specific $\mathrm{CD}^{+} \mathrm{T}$-cell activation (not shown).
The immune response detected in DNA-inoculated mice appeared much stronger than what we previously observed in mice injected with in vitro produced engineered exosomes. ${ }^{13}$ A direct comparative experiments cannot be run in view of the different nature of the two immunogens. However, we noticed that the DNA inoculation elicited an E7-specific $\mathrm{CD}^{+} \mathrm{T}$-cell activation strong enough to be clearly detected without the in vitro, peptide-directed stimulation/expansion of specific $\mathrm{CD} 8^{+} \mathrm{T}$ lymphocytes which, on the contrary, was required to detect the immune response in mice inoculated with in vitro produced exosomes. ${ }^{13}$ This apparently stronger immunogenicity was likely a consequence of the continuous release from DNA-recipient muscle cells of immunogenic exosomes ready to be internalized by both local and distal antigen-presenting cells. Differently, it is known that both in vitro and ex vivo produced exosomes have a quite short half-life upon injection, ie, about 2 minutes, with a prompt accumulation in liver and spleen, and only residual amounts detectable after 4 hours. ${ }^{25-28}$ The detection of fluorescent exosomes in plasma of mice inoculated with Nef ${ }^{\text {mut}} / \mathrm{GFP}$ expressing vector represented a key finding supporting the idea that engineered exosomes can indeed be produced upon DNA injection. The lack of Nef-specific $\mathrm{CD}^{+} \mathrm{T}$-immune response in mice injected with wt Nef highlighted the importance for the immune response of the efficient association with exosomes, meanwhile excluding the involvement of other Nef functions. Similarly, no E7-specific $\mathrm{CD}^{+}$ T-cell immune response was detectable in mice injected with vector expressing E7 alone, which per se associates

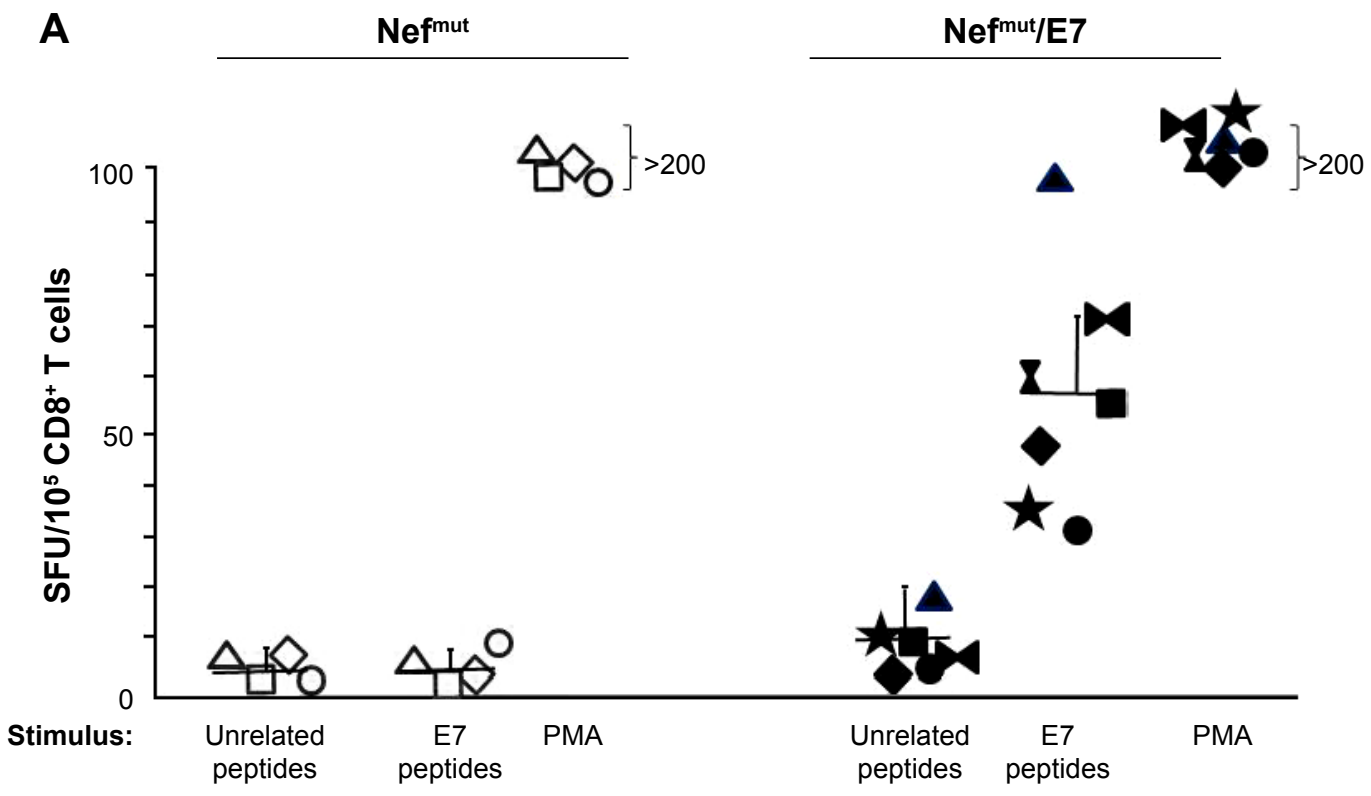

Figure 6 (Continued) 

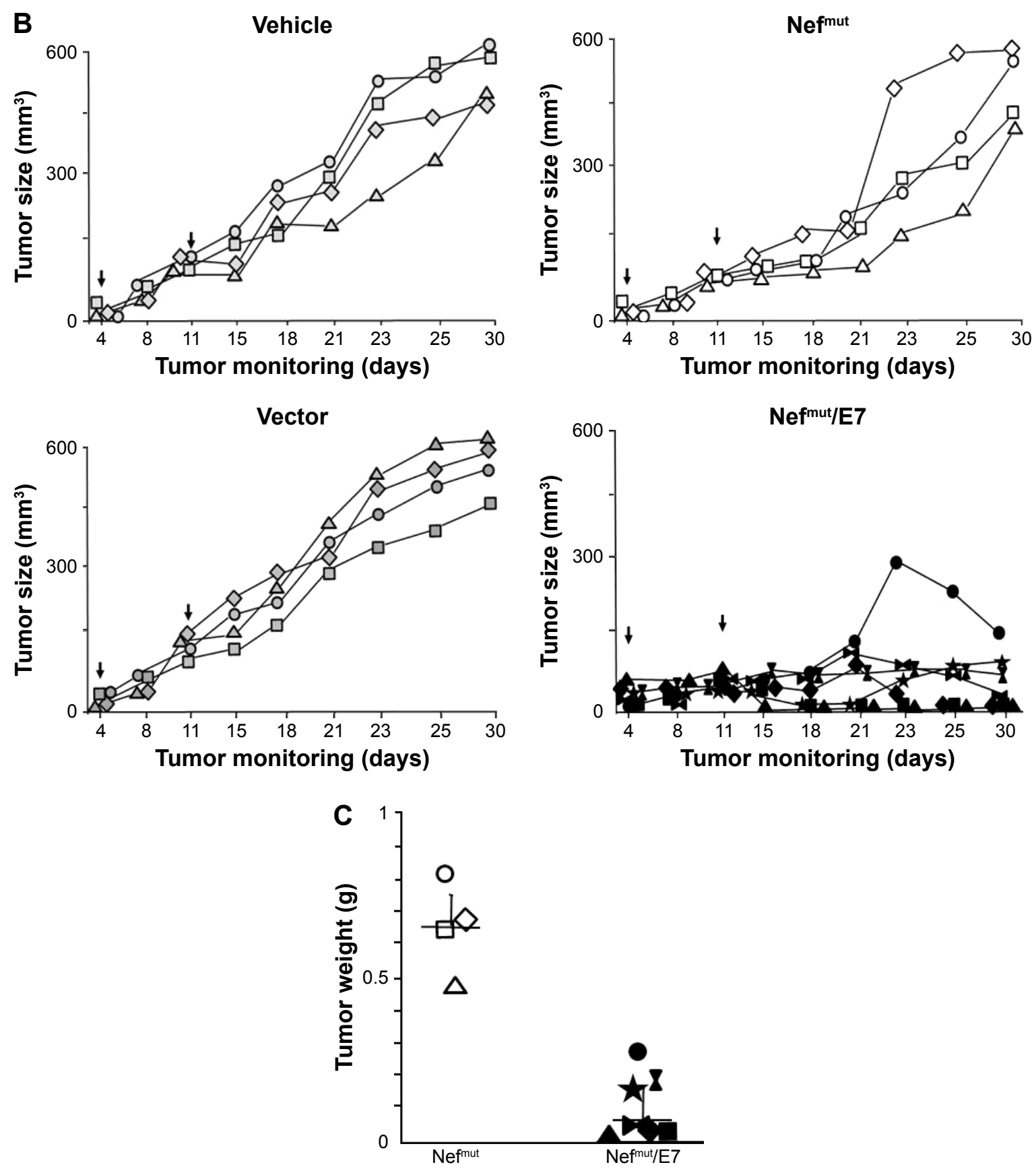

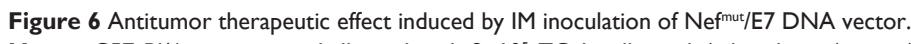

Notes: C57 Bl/6 mice were challenged with $2 \times 10^{5} \mathrm{TC}-\mathrm{I}$ cells, and 4 days later (arrows), when tumor masses became detectable by palpation, inoculated with either Nefmut/E7 vector (seven mice) Nefmut vector, empty vector, or vehicle (four mice per group). The DNA inoculations were repeated at day II (arrows) after tumor cell implantation, and the growth of tumor mass was followed over time. (A) E7-specific CD8 ${ }^{+}$T-cell response as detected by IFN- $\gamma$ Elispot assay was carried out with PBMCs recovered from retro-orbital bleeding 7 days after the last immunization and cultivated for 16 hours in the presence of either unrelated or E7 peptides. As control, PBMCs were incubated with $5 \mathrm{ng} / \mathrm{mL}$ of PMA and $500 \mathrm{ng} / \mathrm{mL}$ of ionomycin. Shown are the number of SFU/ $10^{5}$ cells from triplicate wells seeded with splenocytes from mice inoculated with either Nef ${ }^{\text {mut }}$ or Nefmut/E7 vectors. (B) Determination of the tumor size during the 30-day observation time. (C) Weight of tumors from mice injected with either Nef ${ }^{\text {mut }}$ or Nef ${ }^{\text {mut} / E 7 ~ D N A ~ v e c t o r s ~ a t ~ t h e ~ t i m e ~ o f ~ s a c r i f i c e . ~ S h o w n ~ a r e ~ t h e ~ r e s u l t s ~ o f ~ o n e ~ r e p r e s e n t a t i v e ~ o f ~ t w o ~ i n d e p e n d e n t ~ e x p e r i m e n t s . ~}$

Abbreviations: IM, intramuscular; PBMCs, peripheral blood mononuclear cells; PMA, phorbol I2-myristate I3-acetate; SFU, spot-forming unit.

with exosomes poorly, in the presence, however, of a well detectable anti-E7 antibody production. This result further supports the idea that high levels of antigen incorporation into exosomes are mandatory to elicit a strong antigen-specific CTL activity.
Most important, the key role of endogenously engineered exosomes in the antigen-specific immune response was demonstrated by the evidence that exosomes isolated from plasma of DNA-injected mice were immunogenic when inoculated in naïve recipient mice. On the other hand, the 


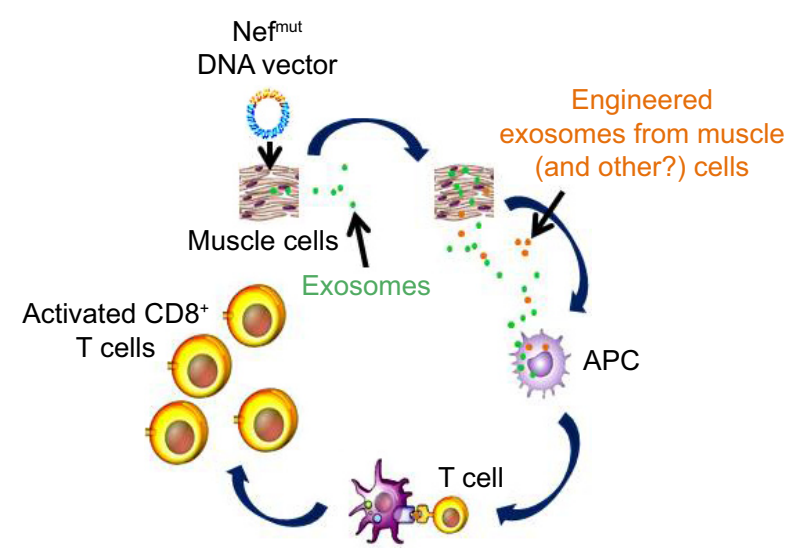

Figure 7 Mechanism of CTL activation induced by inoculation of Nefmut-based DNA vectors.

Notes: Muscle (and possibly other) cells expressing the injected DNA vector release both unmodified and engineered exosomes. These latter, once internalized by APCs induce priming/activation of $\mathrm{CD}^{+} \mathrm{T}$-lymphocytes specific for the antigens uploaded in engineered exosomes.

Abbreviations: APC, antigen-presenting cell; CTL, cytotoxic T lymphocyte.

DNA-induced immune response appeared fast and strong enough to efficiently counteract the growth of syngeneic tumor cells implanted before the immunizations. The mechanism underlying the $\mathrm{CD} 8^{+} \mathrm{T}$-cell activation induced by inoculation of Nef ${ }^{\text {mut }}$-based DNA vectors are depicted in Figure 7. Muscle cells (and, possibly, other cell types) expressing the injected DNA vector release engineered exosomes. These are expected to be internalized by antigen-presenting cells. The internalization of $\mathrm{Nef}^{\text {mut }}$-based exosomes leads to crosspresentation of the associated antigens and, by consequence, priming of antigen-specific $\mathrm{CD}^{+} \mathrm{T}$-cells. Boosting of the immune response can be generated, besides the second round of DNA injection, by the continuous release of immunogenic exosomes from DNA recipient cells.

\section{Conclusion}

The data reported here allow us to propose a novel strategy to induce CTL immunity based on endogenously engineered exosomes. The major advantages of our vaccine platform are the cost-effectiveness of immunogens, ease of storage, potent immunogenicity, and significant intrinsic flexibility in terms of choice of the immunogen.

\section{Acknowledgments}

This work had Istituto Superiore di Sanità (ISS) review board approval and was supported by the grant of "Ricerca Finalizzata" project RF-2010-2308334 from the Ministry of Health, Italy. We thank Massimo Sanchez, ISS for help with the FACS analysis of free exosomes; Andrea Giovannelli, Claudia d'Agostino, Paolo Frassanito, and Carlo Giovannelli,
ISS, for their support in animal housing and experimentation; and Pietro Arciero and Stefania de Menna, ISS, for technical support.

\section{Disclosure}

The authors report no conflicts of interest in this work.

\section{References}

1. Schorey JS, Cheng Y, Singh PP, Smith VL. Exosomes and other extracellular vesicles in host-pathogen interactions. EMBO Rep. 2015; 16:24-43.

2. Forterre A, Jalabert A, Berger E, et al. Proteomic analysis of $\mathrm{C} 2 \mathrm{C} 12$ myoblast and myotube exosome-like vesicles: a new paradigm for myoblast-myotube cross talk? PLoS One. 2014;9:e84153.

3. Guescini M, Guidolin G, Vallorani L, et al. C2C12 myoblasts release micro-vesicles containing mtDNA and proteins involved in signal transduction. Exp Cell Res. 2010;16:1977-1984.

4. Romancino DP, Paterniti G, Campos Y, et al. Identification and characterization of the nano-sized vesicles released by muscle cells. FEBS Lett. 2013;587:1379-1384.

5. Dai S, Wei D, Wu Z, et al. Phase I clinical trial of autologous ascitesderived exosomes combined with GM-CSF for colorectal cancer. Mol Ther. 2008; 16:782-790.

6. Escudier B, Dorval T, Chaput N, et al. Vaccination of metastatic melanoma patients with autologous dendritic cell (DC) derived-exosomes: results of the first phase I clinical trial. $J$ Transl Med. 2005;3:10.

7. Hartman ZC, Wei J, Glass OK, et al. Increasing vaccine potency through exosome antigen targeting. Vaccine. 2011;29:9361-9367.

8. Xiu F, Cai Z, Yang Y, Wang X, Wang J, Cao X. Surface anchorage of superantigen SEA promotes induction of specific antitumor immune response by tumor-derived exosomes. $J$ Mol Med. 2007;85:511-521.

9. Usami Y, Popov S, Popova E, Inoue M, Weissenhorn W, Göttlinger HG. The ESCRT pathway and HIV-1 budding. Biochem Soc Trans. 2009; 37:181-184.

10. Lenassi M, Cagney G, Liao M, et al. HIV Nef is secreted in exosomes and triggers apoptosis in bystander CD4+ T cells. Traffic. 2010;11:110-122.

11. Foster JL, Denial SJ, Temple BR, Garcia JV. Mechanisms of HIV-1 Nef function and intracellular signaling. J Neuroimmune Pharmacol. 2011; 6:230-246.

12. Lattanzi L, Federico M. A strategy of antigen incorporation into exosomes: comparing cross-presentation levels of antigens delivered by engineered exosomes and by lentiviral virus-like particles. Vaccine. 2012; 30:7229-7237.

13. Di Bonito P, Ridolfi B, Columba-Cabezas S, et al. HPV-E7 delivered by engineered exosomes elicits a protective $\mathrm{CD} 8^{+} \mathrm{T}$ cell-mediated immune response. Viruses. 2015;7:1079-1099.

14. Keppler OT, Allespach I, Schüller L, Fenard D, Greene WC, Fackler OT. Rodent cells support key functions of the human immunodeficiency virus type 1 pathogenicity factor Nef. J Virol. 2005;79: $1655-1665$

15. D'Aloja P, Olivetta E, Bona R, et al. Gag, vif, and nef genes contribute to the homologous viral interference induced by a nonproducer human immunodeficiency virus type 1 (HIV-1) variant: identification of novel HIV 1-inhibiting viral protein mutants. J Virol. 1988;72: 4308-4319.

16. Massa S, Simeone P, Muller A, Benvenuto E, Venuti A, Franconi R. Antitumor activity of DNA vaccines based on the human papillomavirus-16 E7 protein genetically fused to a plant virus coat protein. Hum Gene Ther. 2008;19:354-364.

17. Gorer PA. Studies in antibody response of mice to tumour inoculation. Br J Cancer. 1950;4:372-379.

18. Théry C, Amigorena S, Raposo G, Clayton A. Isolation and characterization of exosomes from cell culture supernatants and biological fluids. Curr Prot Cell Biol. 2006;3. 
19. Rieu S, Géminard C, Rabesandratana H, Sainte-Marie J, Vidal M. Exosomes released during reticulocyte maturation bind to fibronectin via integrin alpha4beta1. Eur J Biochem. 2000;267:583-590.

20. Bauer S, Heeg K, Wagner H, Lipford GB. Identification of $\mathrm{H}-2 \mathrm{~Kb}$ binding and immunogenic peptides from human papilloma virus tumour antigens E6 and E7. Scand J Immunol. 1995;42:317-323.

21. Liang X, Fu TM, Xie X, Emini EA, Shiver JW. Development of HIV-1 Nef vaccine components: immunogenicity study of Nef mutants lacking myristoylation and dileucine motif in mice. Vaccine. 2002;20: 413-421

22. Di Bonito P, Grasso F, Mochi S, et al. Serum antibody response to Human papillomavirus (HPV) infections detected by a novel ELISA technique based on denatured recombinant HPV16 L1, L2, E4, E6 and E7 proteins. Infect Agent Cancer. 2006;1:6.

23. Arenaccio C, Chiozzini C, Columba-Cabezas S, Manfredi F, Federico M. Cell activation and HIV-1 replication in unstimulated CD4 ${ }^{+} \mathrm{T}$ lymphocytes ingesting exosomes from cells expressing defective HIV-1. Retrovirology. 2014;11:46.

24. Greenberg ME, Bronson S, Lock M, Neumannn M, Pavlakis GN, Skowronski J. Co-localization of HIV-1 Nef with AP-2 adaptor protein complex correlates with Nef-induced CD4 down-regulation. EMBOJ. 1998;16:6764-6776.
25. Imai $T$, Takahashi $Y$, Nishikawa $M$, et al. Macrophage-dependent clearance of systemically administered B16BL6-derived exosomes from the blood circulation in mice. J Extracell Vesicles. 2015;4:26238.

26. Morishita M, Takahashi Y, Nishikawa M, et al. Quantitative analysis of tissue distribution of the B16BL6-derived exosomes using a streptavidinlactadherin fusion protein and iodine-125-labeled biotin derivative after intravenous injection in mice. J Pharm Sci. 2015;104: $705-713$.

27. Takahashi Y, Nishikawa M, Shinotsuka H, et al. Visualization and in vivo tracking of the exosomes of murine melanoma B16-BL6 cells in mice after intravenous injection. J Biotechnol. 2013;165:77-84.

28. Yamashita T, Takahashi Y, Nishikawa M, Takakura Y. Effect of exosome isolation methods on physicochemical properties of exosomes and clearance of exosomes from the blood circulation. Eur J Pharm Biopharm. 2016;98:1-8.
International Journal of Nanomedicine

\section{Publish your work in this journal}

The International Journal of Nanomedicine is an international, peerreviewed journal focusing on the application of nanotechnology in diagnostics, therapeutics, and drug delivery systems throughout the biomedical field. This journal is indexed on PubMed Central, MedLine, CAS, SciSearch $®$, Current Contents $\AA /$ Clinical Medicine,

\section{Dovepress}

Journal Citation Reports/Science Edition, EMBase, Scopus and the Elsevier Bibliographic databases. The manuscript management system is completely online and includes a very quick and fair peer-review system, which is all easy to use. Visit http://www.dovepress.com/ testimonials.php to read real quotes from published authors.

Submit your manuscript here: http://www.dovepress.com/international-journal-of-nanomedicine-journal 